\title{
Building a Resilient Wheat Seed System to Resist Rust Risks in Ethiopia
}

\author{
Abebe A. Gizaw ${ }^{1}$ and Karta K. Kalsa ${ }^{2}$ \\ 1. Ethiopian Institute of Agricultural Research (EIAR), Addis Ababa P.O. Box 2003 Code 1000, Ethiopia \\ 2. EIAR, Kulumsa Research Center, Asella P.O. Box 489, Ethiopia
}

\begin{abstract}
This study is a review of existing reports and summary of some field experiences aiming at building of a resilient wheat seed system to resist rust risks in Ethiopia. Practical gaps in the wheat seed system were identified with regard to understanding of seed system factors that build, or undermine resilience to rust risks. The study has recognized that the formal seed multiplication schemes are too slow to respond to the ever increasing frequencies of wheat rust outbreaks. Therefore, it is indicated that new approaches such as pre-release and farmer based seed multiplication schemes are helpful in insuring availability of seed of rust resistant wheat varieties to the small farmers.
\end{abstract}

Key words: Wheat, seed system, resilience, rust.

\section{Introduction}

Seed with improved genotype is an important component of enhancing crop productivity for the ever increasing global population. Secured access to seed of improved varieties has a direct link to food security [1] indicating that seed supply systems are integral part of any agricultural growth program.

Wheat is one of the most important grain crops grown in Ethiopia with a total annual production of more than 3.4 million MT [2]. The crop supports 4.8 million small scale farmers on 1.6 million hectares of land. However, periodic rust epidemics and frequent break downs of rust resistance genes in wheat varieties [3] have become important challenges to food security in the wheat based system of the country. Though development of rust resistant wheat varieties has been given due attention, until recent years, building resilient wheat seed supply systems to rust risks remained unexplored and unpracticed. The wheat seed supply systems are featured with lacks of varietal diversity (dominated by few varieties with rust

Corresponding author: Karta K. Kalsa, M.Sc., research field: seed science. resistance), inadequate seed availability (mainly state controlled formal supply system), limited accessibility by resource poor farmers, and inadequate utilization/quality control system.

Therefore, this article addresses practical gaps in the wheat seed system, helping to improve understanding of seed system factors that build, or undermine, resilience to rust risks. We provide an overview of wheat seed supply systems in Ethiopia, and we will summarize and discuss lessons learned from experience in the field.

\section{The Wheat Seed System of Ethiopia}

Ethiopian farmers acquire wheat seed for planting from two distinct categories of sources: the formal and informal (traditional) sources [4].

\subsection{The Formal System}

The formal seed system is governed by policies and regulations stipulated in different public proclamations that were put in place since 1990s [5]. Implementing roles of those seed policies and regulations is the responsibility of Ministry of Agriculture. In the formal seed system quality control 
is enforced so that any seed that is intended for commercial purposes should comply with the Ethiopian Seed Standards.

Several parties such as Ethiopian NARS (National Agricultural Research System), public and private seed enterprises, and farmers' cooperative unions are involved in the formal wheat seed supply system (Fig. 1). The role of the formal sector is breeding and releasing new varieties, multiplication and supply of breeder, pre-basic, basic and certified seeds, based on nomenclature of the OECD (Organization for Economic Cooperation and Development).

Hence, the formal seed system starts with variety evaluation and release followed by variety maintenance and early generation seed multiplication by NARS which mainly encompasses the EIAR
(Ethiopian Institute of Agricultural Research), RSARIs (Regional State Agricultural Research Institutes) and universities (Haramaya, Hawassa, and Jimma). The NARS is responsible for releasing and commercializing new varieties through special and standard release procedures [6].

Through the special release scheme, varieties which are already registered and commercialized in another country and proved to be adaptable in Ethiopia are shopped for rapid technology deployment. Durable rust resistant wheat varieties such as Picaflor\#1 and Damphe\#1 were registered in 2010 with names such as Kakaba and Danda'a, respectively, within this scheme to mitigate the Ug99 race of stem rust [3]. For special releases, the applicant discloses the following information: country of release, confirmation for

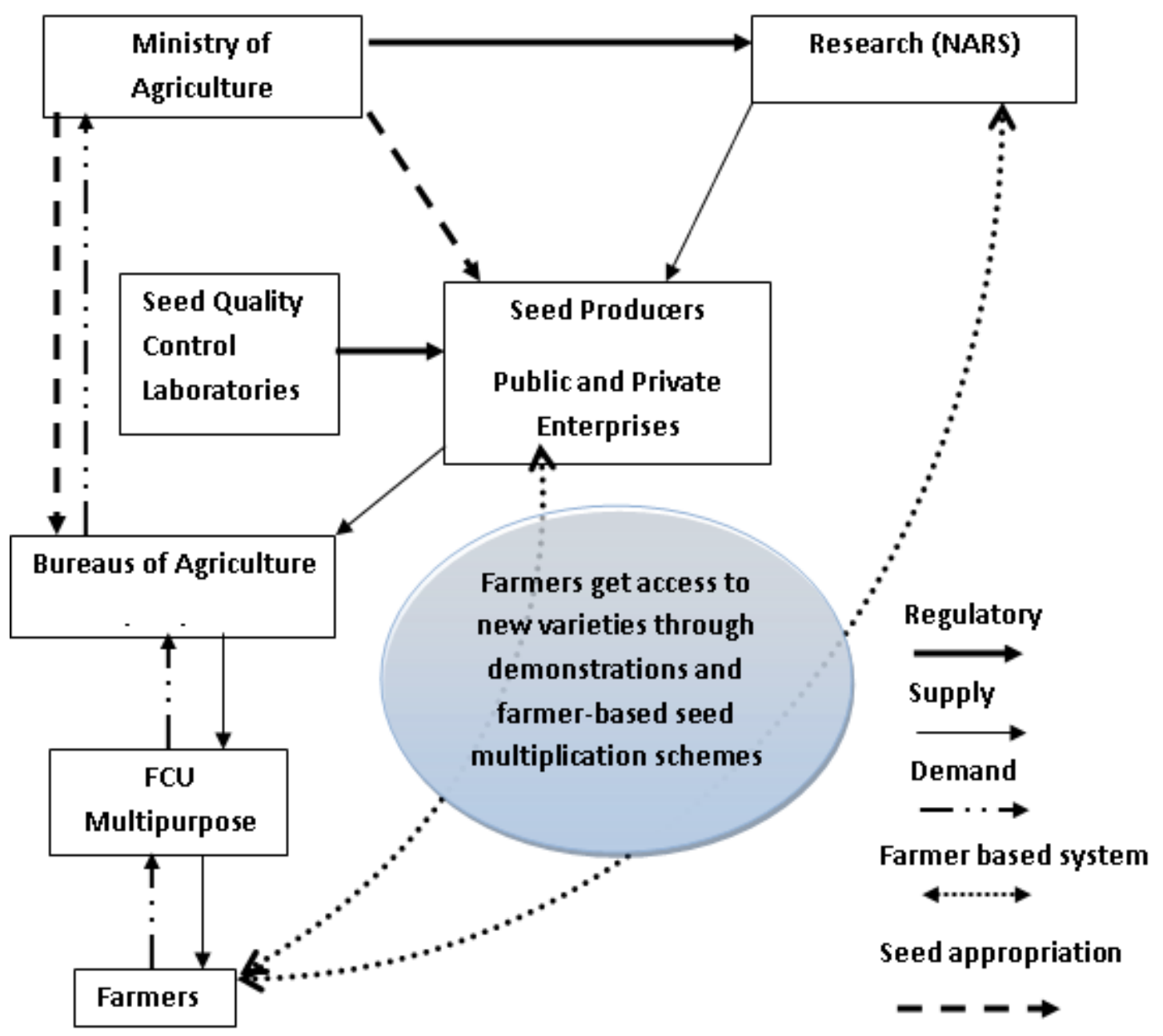

Fig. 1 Current organization of formal wheat seed supply system in Ethiopia. The Ministry of Agriculture has regulatory and commercial seed appropriation role. 
being released elsewhere, one season performance data at a minimum of six environments, technical committee evaluation report, and seed production plan to meet the demand for certified seed [6]. The approach is an important strategy for building rust resilient wheat seed supply system because it enables the system to quickly supply resource to poor farmers with varieties that do not incur cost of fungicide application.

Variety release in the formal seed system also follows a standard procedure with several stages and locations. Under the standard release procedure, any variety intended for release must be tested for a minimum of two seasons and three locations variety trial or a systematically analyzed six environment data [6]. This procedure, because the amount of germplasm acquired is very small in the beginning, takes too long time to make rust resistant new varieties accessible to small farmers. However, application of accelerated seed multiplication programs (Section 4) within this scheme can enhance immediate availability of new varieties.

Breeding institutions are expected to make available a minimum of three tons of wheat breeder's seed at time of release of new varieties and responsible for subsequent variety maintenance [7]. The former case has not been practical until the new approach of accelerated seed multiplication scheme was implemented on rust resistant varieties. Traditionally, seed of new varieties is increased at research centers starting with very small amount of breeder's seed and progresses to pre-basic and basic seed. While more than 10 varieties were newly released between 2001 and 2010 under research centers of Ethiopian Institute of Agricultural Research Institute, only 38.5 tons of breeders seed was available in 10 year (unpublished data). The amount includes breeder's seed multiplied for variety renewal every year. The traditional approach, therefore, was extremely slow and did not enhance immediate access of disease resistant varieties by small farmers hence undermining resilience of wheat seed system to rust risks.

The formal wheat seed system is dominated by public seed enterprises (which are independently organized at Federal and Regional States level). Public enterprises under the Federal Government include ESE (Ethiopian Seed Enterprise) and BADE (Bale Agricultural Development Enterprise). Since early 1980s the ESE has been largest wheat seed supplier with adequate facility for wheat seed processing and storage. In Ethiopia, the present huge volume and the rapid growth in production and demand offers a unique opportunity for the development of the seed sector and trade in varieties and planting materials. So, only the two public enterprises could not supply enough seed for the demand from the farmers. Therefore, additional three public seed enterprises are established by the Regional States governments such as OSE (Oromiya Seed Enterprise), ASE (Amhara Seed Enterprise), and SSE (South Seed Enterprise) with the aim of improving access of small farmers to improved seed.

The private sector role in wheat seed production and distribution is limited because of the unattractive profit margins. However, emerging Farmers' Cooperative Unions such as Ediget Union are moderately involved in wheat seed multiplication.

Seed demand assessment in Ethiopia is done usually one season before so that seed of those varieties for which the farmers showed preference is produced during that season and made available the coming season. To conduct seed demand assessment in Ethiopia the following forcasting/assessment methods are being employed:

(1) collect farmers seed demand directly from farmers by DA's,

(2) trend analysis using past trend data,

(3) area of land to be coverd by improved seed and the amount seed required.

The MoA (Ministry of Agriculture) estimates seed demand using bottom-up approach whereby DAs (Development Agents) in collaboration with 
development team and rural Kebele Administration collect seed need from individual farmers, in terms of crop variety and quantity seeds of each variety. Such data are compiled by the Input Coordination Unit's of BoA (Bureau of Agriculture) at districts, zones and region levels so as to show seed demand of the region. These demands are adjusted based on trends of improved seed consumption in the previous year's and government development plans. However, the demand assessment is not linked with promotion of new potential varieties and new demand creation. The estimated regional seed requirement is apportioned to the various producers (i.e. Ethiopian Seed Enterprise, Oromiya Seed Enterprise, Bureau of Agriculture and private companies), though the latter could produce what they were supposed to produce on the basis of their capacity as well as resources. Based on the country's certified seed demand, the actual need of source seed to be multiplied by different research centers is fixed through back calculation from the certified to breeder seed depending on the multiplication rate of the crop.

Due to the fact that the demand was collected only from the farmers' side they express demand only to those varieties that they know before, than those released recently with superior performance. Practically the key factors that determine the demand are related with farmers' acquaintance to the varieties, the expected performance of the varieties under the prevailing production conditions (agro-ecology, weather condition, soil fertility, the expected market conditions for the crop, the level of awareness of the farmers about the varieties, and farmers' ability to access the seed.

Wheat seed produced within the formal system by registered public and private seed enterprises is marketed/distributed to small farmers by Cooperative Unions through centralized system which is governed by MoA [8] (Fig. 1). While cooperatives could be easily accessible to farmers to get seed of new varieties, usually the system is inefficient because the seed that reaches farm gates (cooperatives) is not based on effective demand and follows highly centralized scheme [5]. Seed appropriation is done centrally by the MoA (Fig. 1). Such approaches are not helpful in building resilient wheat seed system for rust risks.

Liberalization of the seed business with strict application of elements of the seed law and strengthening of local seed shops could be a vital preference $[5,8,9]$. It is an immediate requirement to organize and promote direct seed marketing systems through agro-dealers who are illegible and ethically capable to undertake seed distribution in the small farming communities. In that case small farmers will have adequate varietal choices depending on their specific demands. It is well recognized that because of seed marketing inefficiencies and other limitations the formal seed supply system covers a tiny proportion of the total wheat field in the country [5] (Table 2). Less than five percent of the total area was covered with seed from the formal sources (Table 1) while there is a significant amount of seed left-over by private companies [5] and the public seed enterprises.

In recent years the wheat seed demand and supply have discrepancies. In 2012 and 2013 nearly half of the demand for improved seed of wheat was covered (Fig. 2). However, a total of 9,829 MT of certified seed of wheat was left-over during 2012 crop season and more than $50 \%$ of the varieties of left-over seed were rust susceptible. The reason behind large amount of left-over seed while the gap between demand and supply is high is due to lack of effective demand and failure of popular varieties to perform under rust pressure. Farmers withdraw their demands when they do not get varieties of their interest, whose varieties are with resistance to yellow and stem rusts [10].

\subsection{The Traditional (Informal or Local) System}

The traditional wheat seed supply system is not 
Table 1 Total area of crop production and the proportion of improved seed coverage in 2012/2013 cropping season in Ethiopia.

\begin{tabular}{llll}
\hline Crop & Total area (ha) & Improved seed (ha) & Proportion (\%) \\
\hline Cereals & $9,601,035$ & 792,946 & 8.3 \\
Pulses & $1,863,445$ & 9,411 & 0.5 \\
Oilseeds & 818,449 & 1,404 & 0.2 \\
Vegetables & 192,555 & 1,331 & 0.7 \\
Root Crops & 203,958 & 2,418 & 1.2 \\
Wheat & $1,627,647$ & 70,743 & 4.3 \\
Maize & $2,013,045$ & 673,747 & 33.5 \\
Total & $\mathbf{1 6 , 3 2 0 , 1 3 4}$ & $\mathbf{1 , 5 5 2 , 0 0 0}$ & $\mathbf{9 . 5}$
\end{tabular}

Source: Central Statistical Agency, 2013.

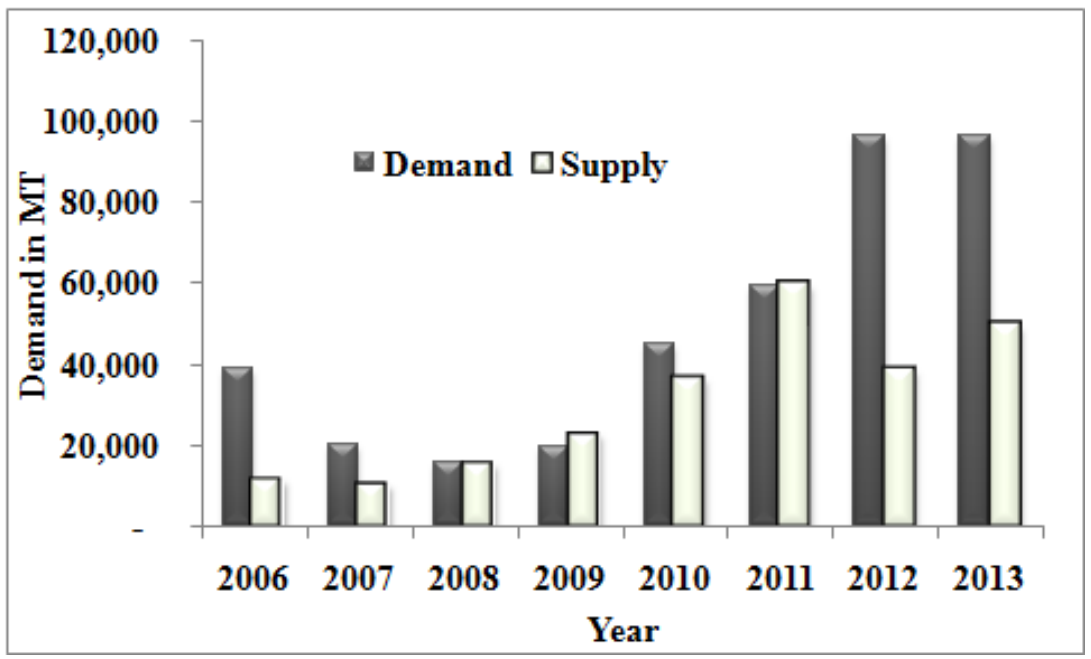

Fig. 2 The national trend of wheat seed demand and supply for seven years. Source: MoA, unpublished data.

bound by laws unlike the formal system. It is a flexible system in which local (older), improved (new), or mixed varieties are used for planting. Activities tend to be integrated and locally organized, and the local system embraces most of the ways in which farmers themselves produce, disseminate, and access seed: directly from their own harvest; through exchange and barter among friends, neighbors, and relatives, and through local grain markets [11]. Taken as a whole, the main feature of the informal seed system is that it is managed by farmers' capacity and skill on fragmented landholdings, where it usually lacks basic processing (drying, cleaning, grading, treating, packing) equipment, basic training and husbandry (rouging) practices [12]. The most important thing is that the seed produced by the informal system is not inspected and certified by the formal regulatory set up.

\section{Building Rust Resilient Wheat Seed System}

The wheat seed system, which is predominated by the traditional supply side in Ethiopia, can be resilient to rust risks if seed security is achieved at individual farmer/community level. Individual farmers/communities are seed secure when availability, access, and quality/utilization of wheat seed are at the acceptable levels.

Availability is secured only when sufficient quantity of adapted rust resistant wheat varieties is within a reasonable proximity and critical period of sowing [13]. While use of farm-saved seed is a common practice in wheat in Ethiopia [4] wheat farmers are interested to renew their seed stocks every 
two to three years depending on yield responses and disease prevalence. However, besides the mismatch of demand and supply with regard to varietal preference, timing of seed distribution to individual farmers is usually delayed until farmers plant their plots with undesirable varieties (from local sources) [10]. Therefore, availability of seed of rust resistant wheat varieties to the farm families should be improved through broadening of initial formal and informal seed multiplication possibilities [13] and liberalization of the seed marketing system with strong institutional set up for maintaining seed quality [5]. Tested approaches such as pre-release seed multiplication, crush seed multiplication programs, and farmer-based seed multiplication should be applied to insure initial availability of seed of rust resistant wheat varieties at farm family/community levels.

Seed secured farm families have the capacity to purchase seed of improved varieties in cash or barter systems. Under constraints of cash availability for input purchase the role of rural microfinance is critical.

\section{Experience from the Field: Ethiopia}

In response to the outbreak of Ug99 a global effort was initiated to supply the wheat grower small farmers with rust resistant wheat varieties [3]. Besides the global initiative, the 2010 yellow rust epidemics in Ethiopia (by which over one third or 591,550 ha of the national wheat area was affected) had triggered implementation of a robust seed multiplication approach to replace widely grown varieties (Kubsa and Galema) which are already susceptible to both yellow and stem rusts. The following sections are approaches followed and results achieved.

In January 2009, initial seeds of durable resistant wheat lines were obtained from CIMMYT (International Maize and Wheat Improvement Center) and ICARDA (International Center for Agricultural Research in Dry Areas) (Table 2). The CIMMYT lines (5 bread wheat and 1 durum) were planted on small plots in Ethiopia at Debre-Zeit and Kulumsa for initial evaluation during 2009 off-season (January to May). In the 2009 main seasons (June to November), selected lines were tested for their adaptation at ten locations across the country both on-research stations and on-farmers' fields. After participatory evaluation by stakeholders, the results were submitted to the national variety release committee for final approval and possible registration. As a result, two varieties namely, Danda'a (Danphe\#1) and Kakaba (Picaflor\#1) were released for large-scale seed multiplication and distribution. These varieties had high yield with combined resistance to stem and yellow rust within only their recommendation domains.

Besides efforts in identification of rust resistant wheat genotypes, pre-release multiplication on candidate varieties was on-going. This technique was used to accelerate variety release which otherwise can be delayed due to shortage of sufficient seed to conduct variety trials and to get sufficient amount of breeder

Table 1 Germplasm introduced for fast track release of Ug99 resistant varieties (2009). All varieties were subject to accelerated seed multiplication in order to mitigate rust risks.

\begin{tabular}{lll}
\hline Lines & Seed source & Seed imported (kg)* \\
\hline Chonte \#1 & CIMMYT & 100 \\
Danphe \#1 & CIMMYT & 100 \\
Munal \#1 & CIMMYT & 100 \\
Picaflor \#1 & CIMMYT & 100 \\
Quaiu \#2 & CIMMYT & 100 \\
Flag 3 & ICARDA & 100 \\
Flag 5 & ICARDA & 50 \\
Amir-2 & ICARDA & 100 \\
Total & & $\mathbf{7 5 0}$ \\
\hline
\end{tabular}


seed upon variety release. In pre-release seed multiplication both promising lines in national variety trials and candidate varieties in variety verification trials were used. In the pre-release scheme, two methods of pr-release seed multiplication were used to accelerate seed multiplication: (i) two crop cycles per year i.e. main season (Meher) and irrigation (off-season) seed production and (ii) planting with low seed rate; low seed rate could provide high multiplication factor for accelerated seed increase with intensive crop management. For example, a seed rate of as low as 40 $\mathrm{kg} / \mathrm{ha}$ was used to produce $2 \mathrm{t} / \mathrm{ha}(\mathrm{MF}=250)$ at Kulumsa, Ethiopia.

In the post-release seed multiplication the EIAR (Ethiopian Institute of Agricultural Research), public seed enterprises and private seed producers were involved. The level of private involvement was limited to a single firm except that some have allocated their land for use by either the EIAR or ESE (Ethiopian Seed Enterprise). The seed multiplication scheme was not limited to rain-fed and traditional wheat growing areas, but was expanded to irrigated areas to undertake multiplication during the off-season. Thus, seed multiplication was twice a year.

In order to ensure the timely dissemination of newly released rust resistant wheat varieties we followed the following strategic approaches. The detailed steps followed are discussed below.

Identification and prioritization of target Weredas (districts) in respective regions. At the inception workshop together with regional agricultural extension and input heads and regional research institutes crop directors we had indentified and prioritized target Weredas based on selected AGP (Agricultural Growth Program) Weredas. In this regard, the key criterion was the severity of rust affection and area coverage of each district by wheat. Since AGP selected Weredas did not include some of the major wheat growing Weredas, based on the suggestions from regions agricultural heads we have included additional 11 Weredas out of AGP selected Weredas. (i) Establishment of innovation platforms: Different stakeholders were identified through multi-stakeholders consultation process. These are federal and regional NARS (National Agricultural Research System), public and private seed producers, development agents and farmers.

(ii) Organization of focal persons at Federal and regional level: At federal level, there was a need to have a focal person from inputs department that coordinates the activities in respective regions. In addition, due to the need to daily follow the logistics in technology distribution and multiplication it was important to assign a seed focal person in each Wereda.

(iii) Identification of suitable rust resistant varieties for the identified target Weredas in each region: Together with experts of the RBoA (Regional Bureaus of Agriculture) and the coordination teams, feasible technologies were selected for each Weredas.

\section{Results and Discussions}

Formal seed multiplication on improved varieties commences after the release of a new variety, and the breeder is responsible for making available only small quantity of nucleus seed during release. The new variety, therefore, needs nearly five generations (almost five years) before it reaches the grain producer farmers. Several varieties of wheat lose their resistance to rusts before they reach farmers through the formal seed production and supply system. If the small farmers have to benefit from the recipe for rust resistance in wheat varieties, sufficient amount of seed must be available for seed producers at release of rust resistant wheat varieties.

The new approach followed to contain the risk of rust prevalence has improved the ultimate access of small farmers to newly released rust resistant wheat varieties in Ethiopia. Newly introduced wheat genotypes were established for seed multiplication as a parallel activity with the variety testing for rust resistance at Debre Zeit and Kulumsa Research Centers of the EIAR. 
Table 2 Pre-release rapid seed multiplication of rust resistant lines at Werer, Ethiopia, in off-season through irrigation (2010) \& amount of seed available at the time of release.

\begin{tabular}{llll}
\hline Lines & Net area (ha) & Average yield (t/ha) & Amount of seed produced (t) \\
\hline Chonte\#1 & 17.01 & 1.523 & 25.9 \\
Danphe\#1* & 17.01 & 1.726 & 29.35 \\
Picaflor\#1* & 21.25 & 2.024 & 43.01 \\
Munal\#1 & 8.5 & 1.823 & 15.502 \\
Quaiu \#2* & 8.14 & 2.399 & 19.55 \\
Total & 71.91 & 1.85 & 133.3 \\
\hline
\end{tabular}

* Rust resistant varieties released in 2010 with names Danda’a, Kakaba, and Gambo, respectively.

A total of $750 \mathrm{~kg}$ seed was sown to harvest almost 26.4 tons in 2009 in main rainy seasons at Kulumsa with average productivity of 4.4 tons per hectare. The amount was increased by five-fold (133 tons) during the off-season of 2010 (Table 3) using irrigation at Werer Research Center, a research center which is completely outside the traditional wheat production agro-ecologies but is furnished with irrigation facility.

At the same time with the pre-release seed multiplication activities, three genotypes namely Damphe\#1, Picaflor\#1, and Quaiu\#2 were proposed for release. Finally, the former two were released for high potential areas (the traditional wheat production agro-ecologies of Ethiopia) and the latter was for irrigated conditions in the lower altitudes. The amount of seed available at release of the three new genotypes were nearly 33.35, 46.71, $24.05 \mathrm{MT}$, respectively. That total amount was sufficient to cover more than 800 ha of seed field.

Regardless of the high cost of pre-release seed multiplication which is triggered by damping seed of un-registered varieties, the approach has extraordinary benefits to mitigate the ever increasing rust risk in the wheat production belts. The ultimate beneficiary is the small holder wheat producer farmers who, through this approach, have access to newly released rust resistant wheat varieties in very short period of time, not more than two years after release while with the normal procedure a newly released variety reached in an average of 10 years. Therefore, national wheat breeding programs can take the approach as risk mitigation under rust pressures.

Under risk prone environments, post-release seed multiplication schemes should be designed to properly respond to natural disasters in the seed system. However, the current scenario of the seed multiplication and supply in the formal system in Ethiopia is in position to contribute less to mitigation of rust risks. A new approach of enhancing availability of rust resistant wheat varieties and broadening initial formal and informal seed supplies and multiplication possibilities should be followed to develop rust resilient wheat seed systems [1].

As part of the rapid seed multiplication process a total area of 26.37 ha of land was covered and an amount of 60.93 tones of pre-basic seed of the two varieties Kakaba (Picaflor\#1) and Danda’a (Danphe\#1) were produced at Kulumsa research center during 2010 main season. At the same time public and private seed enterprises were involved in multiplication of basic seed of those varieties.

The pre-basic seed produced in the main season of 2010 at Kulumsa Research Center was used for 2011 off-season basic seed multiplication at Werer Agricultural Research Center, and on other public and private farms such as Upper Awash Agro-Industry, Robani Farm, Koga, and in Tigray region (Ofla) under the supervision of the Ethiopian Institute of Agricultural Research and Ethiopian Seed Enterprise. Generally, in the off-season an area of 411 ha was covered by Kakaba and Danda'a and a total of 379.5 tones of seed were produced. 


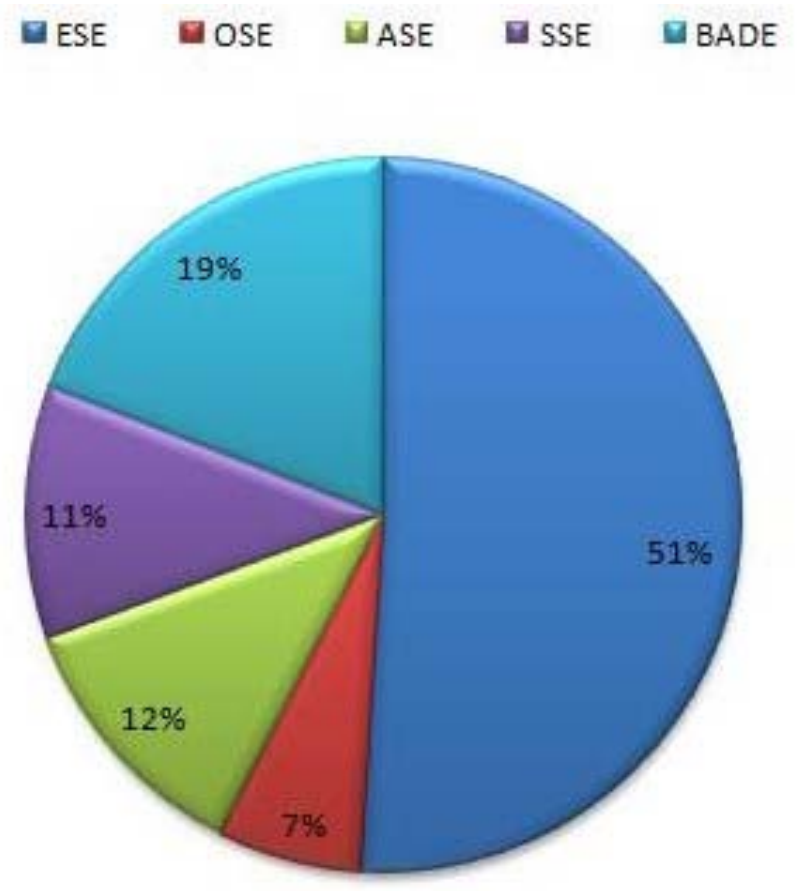

Fig. 3 Proportion by public enterprises of certified seed produced for rust resistant wheat varieties in 2011. The total certified seed was 15,205 MT which is sufficient to cover nearly 101,000ha of wheat land. NB: ESE = Ethiopian Seed Enterprise, OSE = Oromiya Seed Enterprise, ASE = Amhara Seed Enterprise, SSE $=$ Southern Seed Enterprise, BADE=Bale Agricultural Development Enterprise.

Basic seeds multiplied during the off-season of 2011 under the supervision of EIAR and ESE were then used as a source for certified seed multiplication during the main season of 2011 (Fig. 3).

In order to replace the widely grown stem rust susceptible cultivars with resistant ones, a fast track seed multiplication strategy was designed mainly by state owned seed producers. This state owned seed producers multiplied seeds of nationally registered varieties on their own farms as well as on clustered farmers' fields. As a result about 5,383 ha of land were covered with new rust resistant varieties during the main season of 2011 and 15,205 MT of seeds were produced. The seeds were distributed to farmers through regional Bureaus of Agriculture in order to use for the 2012 main season planting. This was sufficient to cover about 121,640 ha of land, area which is by far more than that covered with improved seed in 2013 [2].

This sub-section will deal with another joint initiative between the EIAR and ICARDA. The aim of the joint initiative is to rapidly deploy rust resistant wheat variety to small wheat farmers of Ethiopia. Following two interlinked approaches such as on-farm seed multiplication and popularization/scaling-out of wheat technologies the initiative has played a crucial role in building rust resilient wheat seed supply system.

On-farm seed multiplication schemes are commonly practiced in the wheat seed supply system of Ethiopia. The schemes improve access of small farmers to locally adapted varieties for which there is limited commercial interest [5]. Currently there is increasing interest to promote these schemes because the purely formal seed supply chain is taking extremely longer time to deploy rust resistant wheat varieties.

On-farm seed multiplication included provision of initial seed, and training of farmers and relevant personnel on the importance of inputs and agronomic practices to tackle rust problems. Trainings involved 
farmers, development agents, district experts and district administrators.

Besides on-farm seed multiplication schemes, scaling-up of newly released wheat varieties is playing a crucial role in achieving rust resilient seed system. A program initiated by the EIAR has addressed several agro-ecologies within and outside the wheat production belt of the country since 2009 [2].

Beginning from 2011, rust resistant wheat varieties were popularized and scaled-up to establish rust resilient wheat seed supply system. Based on the previously established technology pre-scaling up schemes of EIAR, the new initiative improved access of 3,110 farmers to improved wheat technologies within three years and benefited 18,660 households (Atilaw and Bishaw, unpublished data). In the course of technology pre-scaling up a total of 2,626 MT seed of rust resistant wheat varieties was produced.

\section{Conclusions and Recommendations}

While the rust risks are always sensible, the wheat seed supply system is still dominated by the formal sector which in practice has slow rate of delivery of rust resistant wheat varieties to small farmers. A robust approach is needed to address the issue of building rust resilient wheat seed supply system. Approaches may include:

- Increasing rate of release of rust resistant varieties in order to avoid dominance of limited number of varieties in the seed supply system (through a special release mechanism and application of pre-release seed multiplications schemes on promising lines).

- Application of crash programs and double cropping using irrigation (the usual steps follow rain fed systems in which new varieties require five to ten years to reach smallholder farmers, by crash programs and double cropping sufficient amount of seed of new varieties can be available for wheat growers). Hence there is a need to consider expanding irrigated wheat (both bread and durum) to boost seed production.
- On-farm seed multiplication should be promoted so that small farmers will get access to seed of new rust resistant wheat varieties with minimum cost and within the required time span. This can be achieved by enhancing community based seed multiplication schemes and promoting involvement of farmers' cooperatives in the seed production and supply system. This should consider promotion of more localized and robust seed systems for improving the diversification of wheat varieties for building resilience to rust risks.

- The wheat technology scaling out and popularization initiatives should be continued over time so that large areas will be addressed. With technology promotion, it is important maximize the role of different seed system actors and the need to promote decentralized seed production to reach diverse wheat agro-ecologies.

- The wheat seed distribution system is confined to the public sector channels. Involvement of agro-dealers should be enhanced in a manner that small farmers will have the easiest access to certified seed packs from the formal sector at their nearby towns and cities. Agro-dealers involvement should include facilitation of development of decentralized facilities for improved seed value addition, including cleaning and packaging [14].

\section{References}

[1] McGuire, S. J., and Sperling, L. 2011. "The Links between Food Security and Seed Security: Facts and Fiction That Guide Response.” Development in Practice 21: 493-508.

[2] CSA (Central Statistical Agency). 2013. Agricultural Sample Survey: Farm Management Practices (Private Peasant Holdings, Meher Season), Central Statistical Agency (CSA), Addis Ababa, Ethiopia.

[3] Singh, R. P., David, P., Hodson, Huerta-Espino, J., Jin, Y., Bhavani, S., Njau, P., Herrera-Foessel, S., Singh, P. K., Singh, S., and Govindan, V. 2011. "The Emergence of Ug99 Races of the Stem Rust Fungus Is a Threat to World Wheat Production." Annual Review of Phytopathology 49: 465-81.

[4] Alemu, D., Rashid, S., and Tripp, R. 2010. Seed System Potential in Ethiopia: Constraints and Opportunities for Enhancing the Seed Sector. IFPRI Seed Diagnostic, 55. 
[5] Alemu, D. 2011. “The Political Economy of Ethiopian Cereal Seed System: State Control, Market Liberalization and Decentralization.” IDS Bulletin 42: 69-77.

[6] Teklewold, A., and Mekonnen, D. 2013. "Varietal Development and Release for Enhancing the Seed System in Ethiopia.” In The Defining Moments in Ethiopian Seed System, edited by Teklewold, A., Fikre, A., Alemu, D., Desalegn, L., and Kirub, A. Addis Ababa: Ethiopian Institute of Agricultural Research (EIAR), 147-68.

[7] NSIA.2001. National Variety Release Procedures and Mechanism. National Seed Industry Agency (NSIA), Addis Ababa, Ethiopia, 73.

[8] Sahlu, Y., Alemu, D., and Atlaw, A. 2013. "Management and Delivery Challenges and Opportunities in the Ethiopian Seed System.” In The Defining Moments in Ethiopian Seed System, edited by Teklewold, A., Fikre, A., Alemu, D., Desalegn, L., and Kirub, A. Addis Ababa: Ethiopian Institute of Agricultural Research (EIAR).

[9] Sperling, L., and S. McGuire. 2010. "Understanding and Strengthening Informal Seed Markets.” Experimental Agriculture 46: 119-36.

[10] Begna, B., Kalsa, K. K., Gemechu, A., Tilahun, D., Usman, S., and Zeberga, A. 2015. "Characterization of the Seed Demand Dynamism in Wheat Growing Areas of
Ethiopia.” Journal of Biology, Agriculture and Healthcare 5: 32-8.

[11] Sperling, L., and Cooper, H. D. 2013. "Understanding Seed Systems and Seed Security." In Improving the Effectiveness and Sustainability of Seed Relief. Rome: Food and Agriculture Organization.

[12] Fikre, A., Wakjira, A., Mekbib, F., and Gebeyehu, S. 2013. "Practices and Developments in the Informal Seed System of Ethiopia." In The Defining Moments in Ethiopian Seed System, edited by Teklewold, A., Fikre, A., Alemu, D., Desalegn, L., and Kirub, A. Addis Ababa: Ethiopian Institute of Agricultural Research (EIAR).

[13] McGuire, S., and Sperling, L. 2013. "Making Seed Systems More Resilient to Stress.” Global Environ. Change 23: 644-53.

[14] Alemu, D., Y., Tesfaye, A. A., and Borman, G. 2013. Ethiopia Seed Entrepreneurship Assessment. ISSD Africa.

[15] Atilaw, A., Alemu, D., Bishaw, Z., Kifle, T., and Kalsa, K. K. 2017. "Early Generation Seed Production and Supply in Ethiopia: Status, Challenges and Opportunities Framework of Early Generation Seed Production” Ethiopian Journal of Agricultural Sciences 27 (1): 99-119. 